\title{
Heat Exchanger Handling MWCNT/Water Nanofluids
}

\author{
Md Jasim Alam \\ M. Tech Scholar \\ Sagar Institute of Science and Technology \\ Gandhi Nagar, Bhopal, (M.P), India \\ mdjasim.engineer@gmail.com
}

\author{
Mr. Yasir Baig \\ Assit. Professor \\ Sagar Institute of Science and Technology \\ Gandhi Nagar, Bhopal, (M.P), India \\ yasir27beg@gmail.com
}

\begin{abstract}
Heat exchangers are an essential part in an assortment of mechanical settings, for example, cooling frameworks, force plants, refineries, and in this way ceaseless endeavor are made to expand their heat transfer efficiencies. Optimize design of helical coil heat exchanger by using fins and the Compare pressure \& temperature by conventional design. The final outcome of the study increase the total heat transfer rate inside the domain. And increase the pressure drop inside the domain. The water outlet temperature decrease up to $315 \mathrm{k}$ and cold outlet temperature increase up to $320 \mathrm{k}$. and total pressure drop increase with the temperature increases. Finally the CFD data were compared with previous data the total pressure drop increase up to $\mathbf{0 . 6 5}$ bar for case-2.the overall efficiency of the system incites up to $5 \%$ to $6 \%$.
\end{abstract}

Keyword: Heat Exchanger, Helically Coil, CFD, ANSYS.

\section{INTRODUCTION}

H New technologies are needed to meet the demand for high heat flux processes to improve heat transfer requirements. Furthermore, there is growing interest in improving the efficiency of existing heat transfer processes. To improve heat transfer in heat exchangers, many active and passive techniques are used nowadays. Conventional heat moves liquids like water, air, greasing up oil and ethylene glycol have extremely helpless warm conductivity contrasted with metals and metal oxides. The particular properties of ordinary liquids can be improved by adding added substances to refrigerants to defeat this limit. The heat move coefficient (improved heat move) can be improved by adding strong particles with high warm conductivity to the refrigerant. To improve the heat move qualities of regular liquids, improving warm conductivity is the key thought.
Improving the warm conductivity of regular liquids by suspending strong particles, for example, millimeter or micrometer measured particles, has been notable for more than 100 years. In any case, bigger particles have numerous troublesome issues like agglomeration, stopping up, disintegration, and so on in the stream way of gadgets. Modern technologies and material synthesis processes cover how to synthesize different nanostructured materials that have very different thermal, mechanical, electrical and optical properties from similar bulk materials. At the confluence of conventional modern nanotechnology and thermal science, to achieve better heat transfer characteristics, nanofluids have been identified as progressive heat transfer fluids. The Argonne National Laboratory in the United States of America first developed the concept of nanofluids in 1995 and discovered its best thermal characteristics. This review provides a quick overview of the important literature presented on the thermal performance of heat exchangers and their application working on nanofluids.

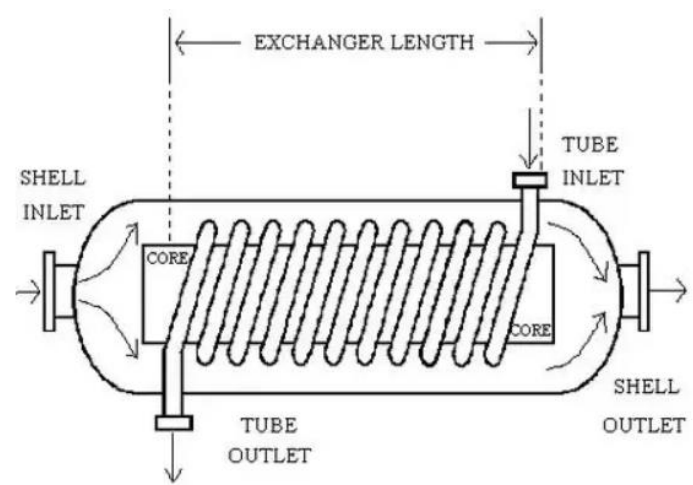

Fig. 1 Helically coiled-tube heat exchanger 


\section{LITERATURE REVIEW}

Mehdi Bahiraei et al. [1] Heat exchangers have effectively demonstrated to be significant gadgets for warm frameworks in numerous businesses. To improve the adequacy of heat exchangers, nanofluids have as of late been utilized as refrigerants in them. As far as the special properties of nanofluids, research concentrates around there have seen exceptional development.

Nima Mazaheri et al. [2] The present work attempts to numerically investigate the hydrothermal properties and energy efficiency of a hybrid nanofluid containing graphene-nanoplatelplatinum composite powder in a three-tube heat exchanger with inserted fins. The nanofluid flows from the inner ring side, while cold water and plain water flow from the tube side and the outer ring side respectively. The ribs are attached to the outer surface of the inner tube. The general heat move coefficient, proficiency and heat move pace of the heat exchanger are improved by expanding the convergence of nanoparticles and the tallness of the blades and diminishing the distance of the balances. The pressure drop is greater with smaller fin spacing and higher fin height, as particles travel greater distances under these conditions.

Reza Rahmani et al. [3] This article reviews and sums up ongoing examinations on the utilization of nanofluids in heat exchangers, including those performed on plate heat exchangers, twin cylinder heat exchangers, shell and cylinder heat exchangers, and conservative heat exchangers. Meanwhile, some captivating parts of consolidating nanofluids with heat exchangers will be introduced. Also, difficulties and openings for future exploration are introduced and talked about.

Umang K Patel et al. [4] In this article, heat exchangers are introduced as significant designing frameworks with a wide assortment of uses, including power plants, refrigeration and cooling frameworks, heat recuperation frameworks, nuclear reactors, chemical processes, and industry food. In order to save energy and achieve precise design of mechanical and chemical devices and systems, heat transfer plays an important role in the design of heat exchangers. To improve efficiency, the geometric D / D parameters are modified for different boundary conditions. The influence of this change on cold water temperature, hot water temperature, cold water velocity, hot water velocity, and Reynolds number with respect to $\mathrm{D} / \mathrm{d}$ is also examined.

\section{OBJECTIVE}

There are following objective of the present work.
- Design and analysis of helical coil heat exchanger

- Optimize heat transfer rate by varying the geometry of fin.

- Validation of pressure \& temperature by conventional design.

\section{METHODOLOGY}

\section{1) STEPS OF WORKING}

Step 1: Collecting information and data related to helically coiled tube heat exchanger.

Step 2: A fully parametric model of the helically coiled tube heat exchanger

Step 3: Model obtained in Step 2 is analyzed using ANSYS 18.2.

Step 4: Finally, we compare the results obtained from ANSYS.

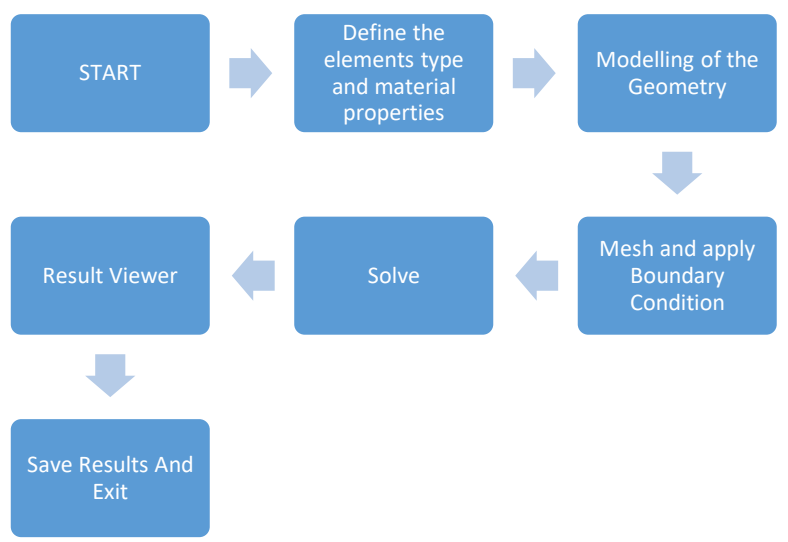

Fig. 2: Setup of working

2) Finite elements analysis

Finite elements analysis is a branch of fluid mechanics that uses numerical analysis and data structures to solve and analyze problems that involve solid structure. For the present work ANSYS 18.2 software used.

ANSYS Capabilities:

In finite element analysis ANSYS software is used that helps engineers for performing the following tasks:

- To build computer prototype, components, transfer CAD models of structures in a system products.

- Enhances the profile of structural member with shape optimization.

- Physical reactions, for example, feelings of anxiety, temperature appropriations, or electromagnetic field examine be contemplated. 
- To reduce production costs optimization of design is done early in the development process.

- Testing of prototypes is done in environments where it otherwise would be undesirable or impossible (for example, biomedical applications).

The graphical user interface (GUI) in ANSYS offers users a simple and interactive approach to documentation, program capacities, orders, and reference material. An instinctive menu framework is utilized by clients to explore the ANSYS program. Input data can be specified using a mouse, keyboard, or a combination of both.

\section{3) STEPS OF ANSYS ANALYSIS}

The different analysis steps involved in ANSYS are mentioned below.

\section{PREPROCESSOR}

The model setup is basically done in preprocessor. The different steps in pre-processing are

- $\quad$ Build the model

- Define materials

- Generation of element mesh

\section{BUILDING THE MODEL}

Table 1 Dimensional parameters of Double helically coiled tube.

\begin{tabular}{|l|l|}
\hline Helically coiled tube & Copper \\
\hline Inner diameter of inner coil (dii) & $5.85 \mathrm{~mm}$ \\
\hline Outer diameter of inner coil (dio) & $6.35 \mathrm{~mm}$ \\
\hline Internal diameter of outer coil (doi) & $12 \mathrm{~mm}$ \\
\hline External diameter of outer coil (doo) & $12.7 \mathrm{~mm}$ \\
\hline Coil pitch(P) & $20 \mathrm{~mm}$ \\
\hline No.of Coils turns(n) & 15 \\
\hline Mean Coil inner diameter (Di) & $100 \mathrm{~mm}$ \\
\hline Mean Coil outer diameter (Do) & $125.35 \mathrm{~mm}$ \\
\hline Thermal conductivity of copper K & $401 \mathrm{~W} / \mathrm{m}$ \\
& $\mathrm{K}$ \\
\hline Thermal conductivity of copper K & 8960 \\
& $\mathrm{~kg} / \mathrm{m} 3$ \\
\hline
\end{tabular}

- Creating a solid model within CATIA

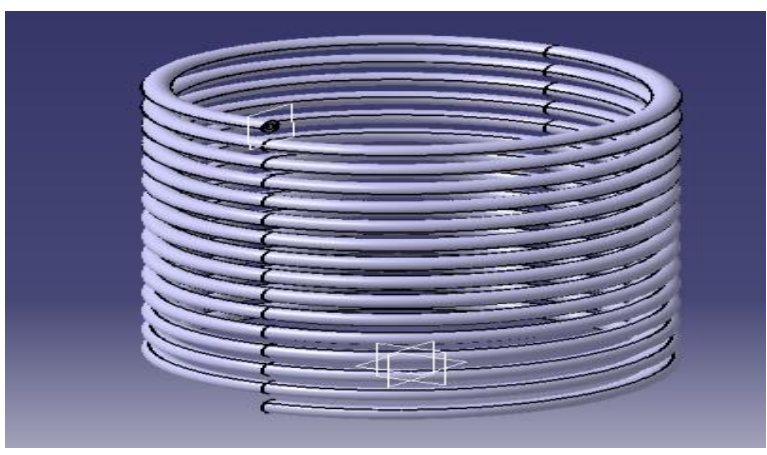

Fig. 3: Overall Creating a solid model within CATIA

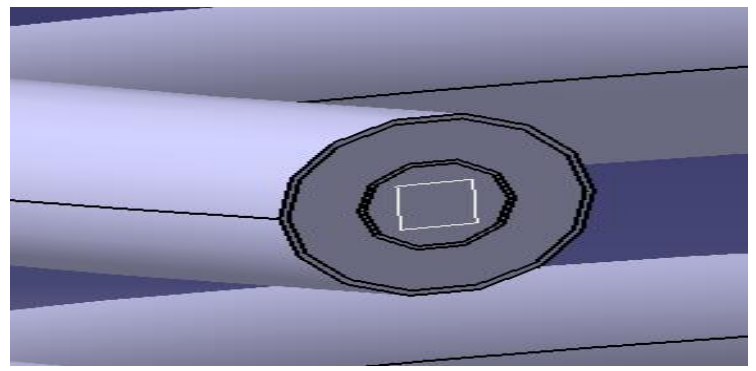

Fig. 4: Section creating a solid model within CATIA

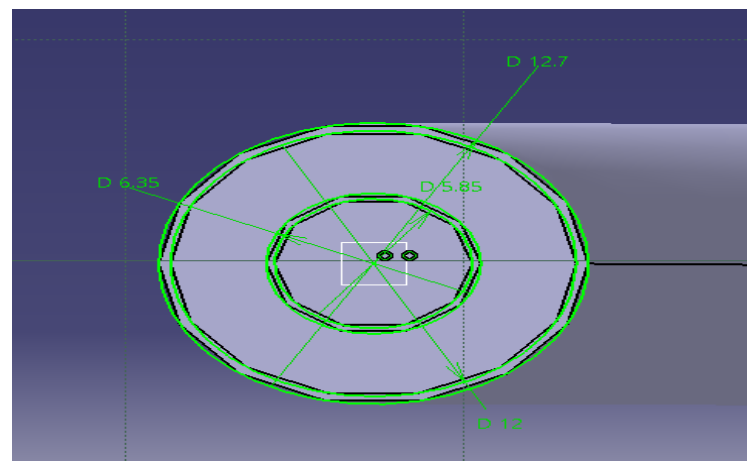

Fig. 5: Detail dimensions

4) Define material:-

Table 2 Testing conditions of MWCNT/water nanofluids

\begin{tabular}{|l|l|}
\hline Constraints & Range/standards \\
\hline Inner tube fluid (Inner coil) & MWCNT/water nanofluids \\
\hline mass flow rate of inner coil & $0.050-0.08 \mathrm{~kg} / \mathrm{m} 3$ \\
\hline Dean number & $1300<\mathrm{De}<2000$ \\
\hline $\begin{array}{l}\text { Initial temperature of coil tube } \\
\text { (inner tube) }\end{array}$ & $305 \mathrm{~K}(32 \mathrm{C})$ \\
\hline Flow velocity of coil tube & $1.2-2 \mathrm{~m} / \mathrm{s}$ \\
\hline $\begin{array}{l}\text { volume concentration of } \\
\text { nanofluid }\end{array}$ & $0.2 \%, 0.4 \%$, and $0.6 \%$ \\
\hline $\begin{array}{l}\text { Density of nanofluid } 0.2 \%, 0.4 \% \\
\text { and0.6\% }\end{array}$ & 1220,1440, and $1660 \mathrm{~kg} / \mathrm{m} 3$ \\
\hline
\end{tabular}




\begin{tabular}{|l|l|}
\hline $\begin{array}{l}\text { Thermal conductivity of } \\
\text { nanofluid } 0.2 \%, 0.4 \% \text { and } 0.6 \%\end{array}$ & $0.62,0.625$, and $0.635 \mathrm{~W} / \mathrm{mK}$ \\
\hline $\begin{array}{l}\text { Specific heat of nanofluid } \\
0.2 \%, 0.4 \% \text { and } 0.6 \%\end{array}$ & 3086,1663 , and $1014 \mathrm{~J} / \mathrm{kgK}$ \\
\hline $\begin{array}{l}\text { Viscosity of nanofluid at } \\
0.2 \%, 0.4 \% \text { and } 0.6 \%\end{array}$ & $0.825,0.83$, and 0.85 \\
\hline $\begin{array}{l}\text { Outer coiled tube fluid (Outer } \\
\text { coil) }\end{array}$ & Hot fluid (Water) \\
\hline Mass flow rate of Inner tube & $0.139 \mathrm{~kg} / \mathrm{m} 3$ \\
\hline Dean number differences & $1300<\mathrm{De}<2000$ \\
\hline $\begin{array}{l}\text { Initial temperature of coil tube } \\
\text { (outer tube) }\end{array}$ & $338 \mathrm{~K}(65 \mathrm{C})$ \\
\hline Outer tube velocity rate & $1.2-2 \mathrm{~m} / \mathrm{s}$ \\
\hline Hot water density & $997 \mathrm{~kg} / \mathrm{m} 3$ \\
\hline Hot water viscosity & 0.7 \\
\hline Hot water specific heat capacity & $4181 \mathrm{~J} / \mathrm{kg} \mathrm{K}$ \\
\hline Hot water thermal conductivity & $0.613 \mathrm{~m} \mathrm{~K}$ \\
\hline
\end{tabular}

5) Define boundary conditions:-

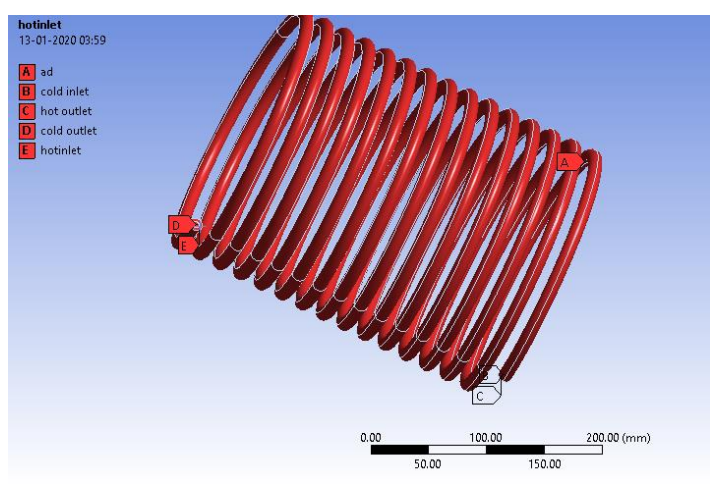

Fig. 6: Define boundary conditions

Table 3 Define boundary conditions

\begin{tabular}{|c|c|c|c|}
\hline Domain & Cold fluid & $\begin{array}{l}\text { Hot } \\
\text { fluid }\end{array}$ & Boundaries \\
\hline \multirow[t]{8}{*}{ Boundary } & Nanofluid inlet & Hot inlet & $\begin{array}{l}\text { Mass-flow } \\
\text { inlet }\end{array}$ \\
\hline & Nanofluid outlet & $\begin{array}{l}\text { Hot } \\
\text { outlet }\end{array}$ & Pressureoutlet \\
\hline & $\begin{array}{l}\text { Wall cold fluid inner } \\
\text { pipe shadow }\end{array}$ & & \\
\hline & $\begin{array}{l}\text { Wall hot fluid outer } \\
\text { pipe shadow }\end{array}$ & $\begin{array}{l}\text { Wall hot } \\
\text { fluid } \\
\text { inner } \\
\text { pipe } \\
\text { shadow }\end{array}$ & Wal \\
\hline & Wall inner pipe & & Wal \\
\hline & Adiabatic wall & & Wal \\
\hline & $\begin{array}{l}\text { Wall hot fluid outer } \\
\text { pipe }\end{array}$ & & Wal \\
\hline & Wall outer pipe & & Wal \\
\hline
\end{tabular}

6) Meshing
Test part modeling is linked to ANSYS 18.2. The coarser mesh is created over the entire effective length of the tube. Figure 1 shows the interlocking of a double spiral tubular heat exchanger used in this CFD analysis. The mesh contains cells that collaborate for triangular and square expressions under boundary conditions. Much effort is devoted to structured hexahedral cells. The smooth mesh is created, the edges and restricted areas of temperature and pressure are meshed. Tables 3 and 4 show the crosslinking information of the test section. This CFD analysis takes into account the following: MWCNT / water nanofluids are incompressible liquids and single phase liquids. The effect of radiation and net convection is neglected. The thermo physical properties do not depend on the temperature. Nanoparticles with uniform dispersion. The flow is hydrodynamic. And a constant heat flow condition is used. Figure. Shows the boundary conditions of the test section.

Table 4 Details of meshing.

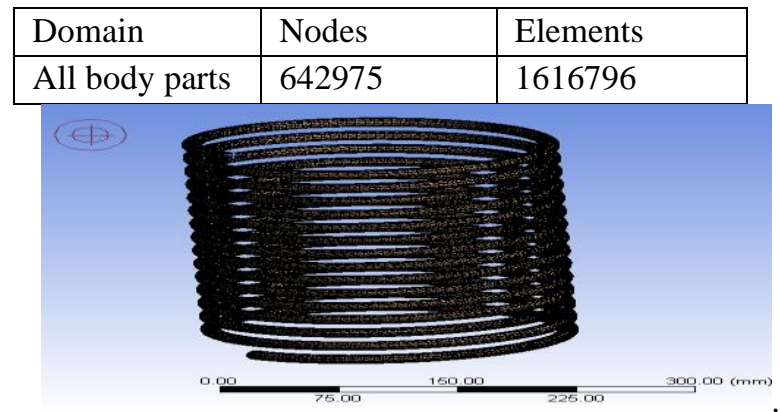

Fig. 7: Over all Meshing

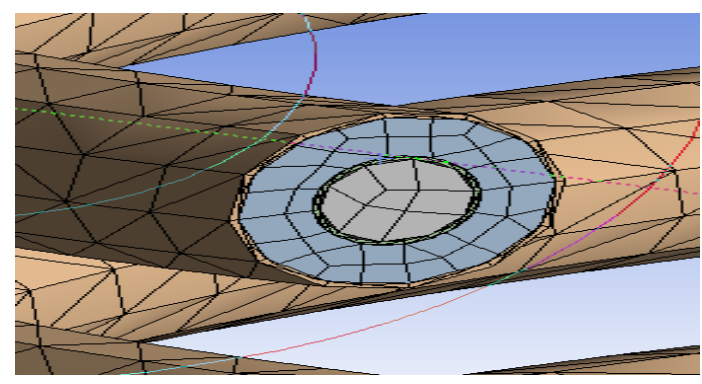

Fig. 8: Section view of Meshing

$\underline{\text { Case-2 }}$ 


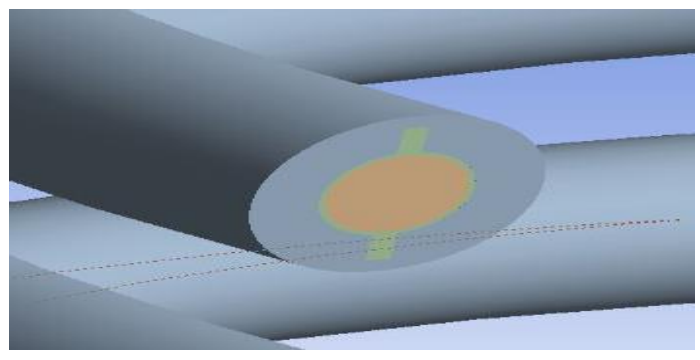

Fig. 9: Case-2 Design

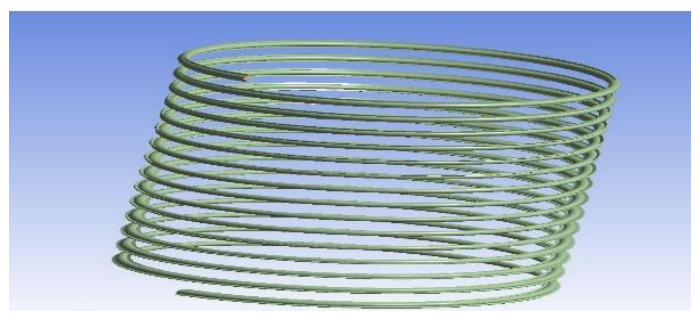

Fig. 10: Case-2 overall Design

Table 5 Details of meshing.

\begin{tabular}{|l|l|l|}
\hline Domain & Nodes & Elements \\
\hline All body parts & 825149 & 2712220 \\
\hline
\end{tabular}

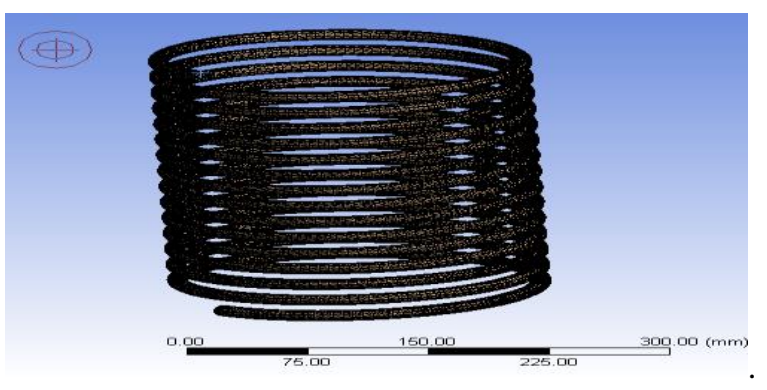

Fig. 11: Case-2 mashing Design

\section{Result:-}

In this study calculated the total pressure drop at differnet volume concentrations with the Dean number range of 1300 2000 .

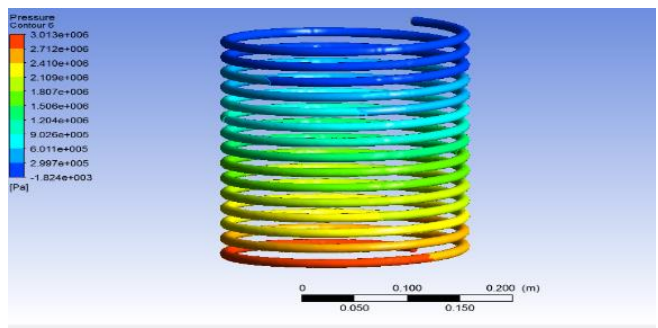

Fig. 12: Pressure contours for case-1

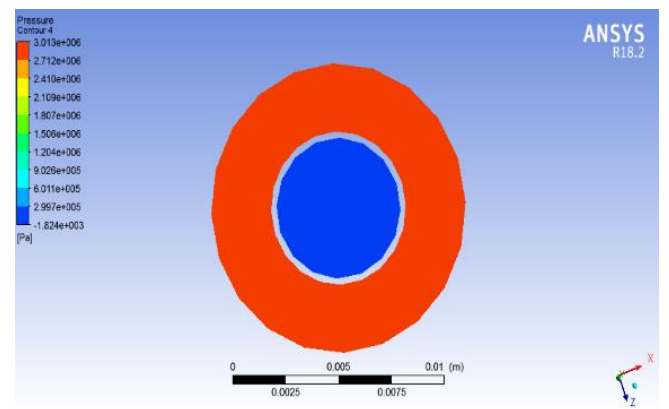

Fig. 13: Pressure contours for case-1(cold outlet and hotinlet)

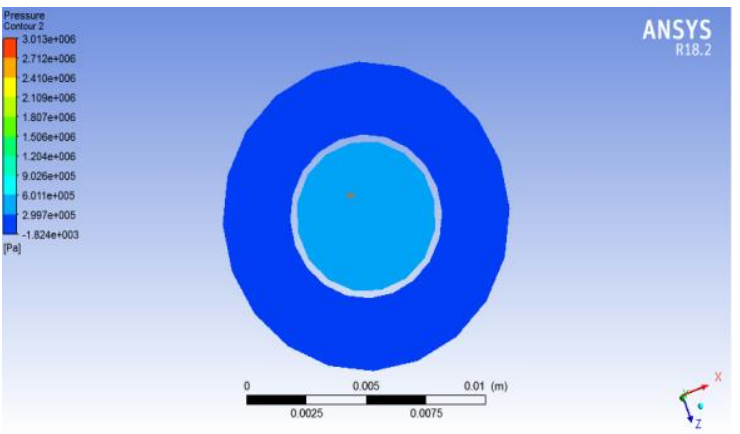

Fig. 14: Pressure contours for case-1 (cold inlet and hot outlet)

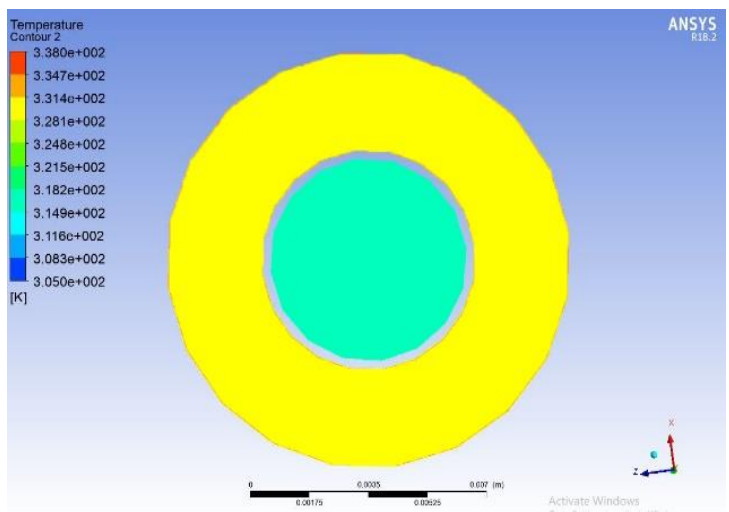

Fig. 15: Temp. Contours for case-1 (0.2 concentration) (cold inlet and hot outlet)

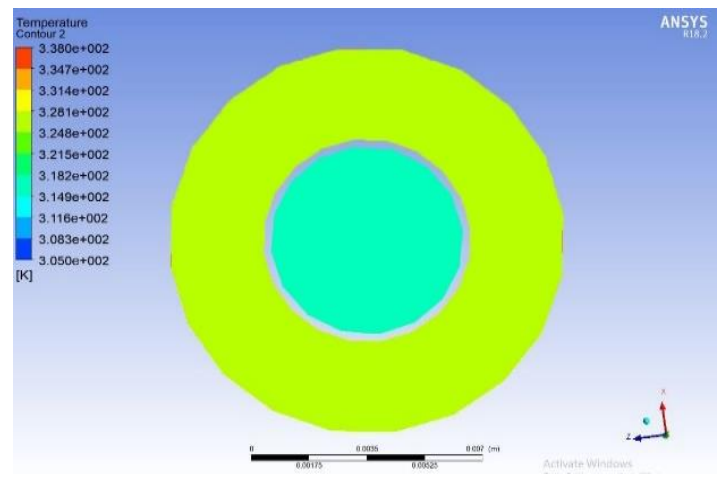

Fig. 16: Temp. Contours for case-1(0.4 concentration) (cold inlet and hot outlet) 


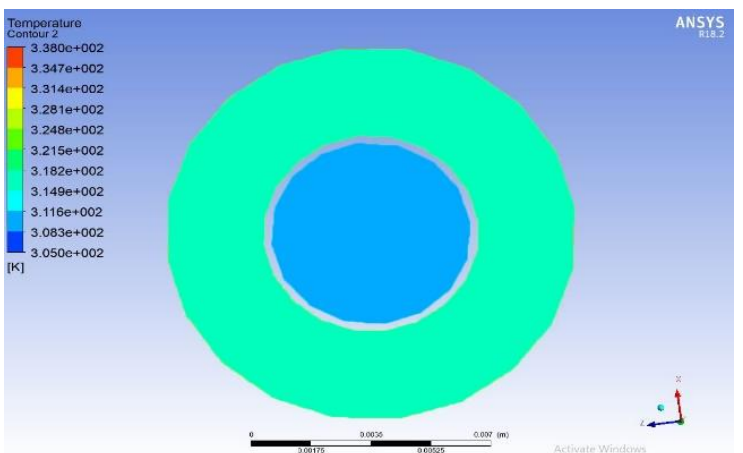

Fig. 17: Temp. Contours for case-1( 0.6 concentration) (cold inlet and hot outlet)

\section{Case-2 result}

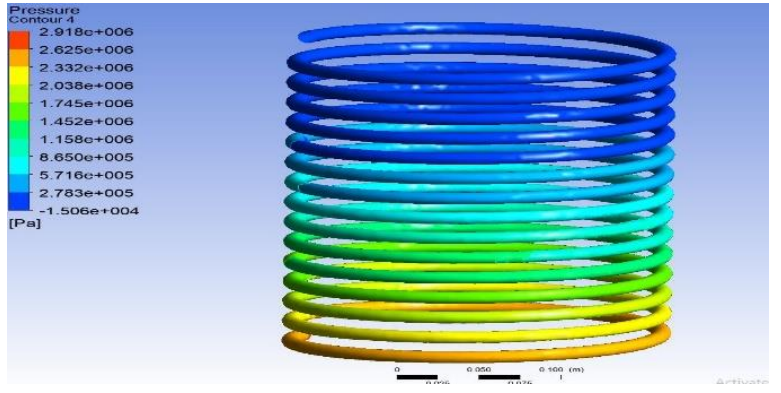

Fig. 18: Temp. Contours for case-2 (0.2 concentration) (cold outlet and hot inlet)

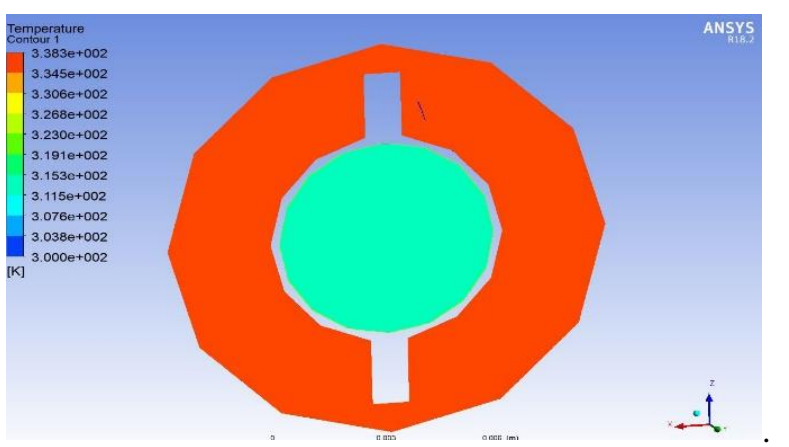

Fig. 19: Temp. Contours for case-2 (0.2 concentration) (cold outlet and hot inlet)

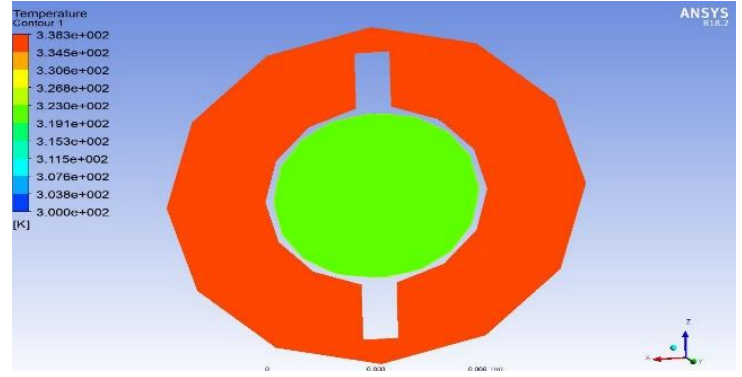

Fig. 20: Temp. Contours for case-2 (0.4 concentration) (cold outlet and hot inlet)

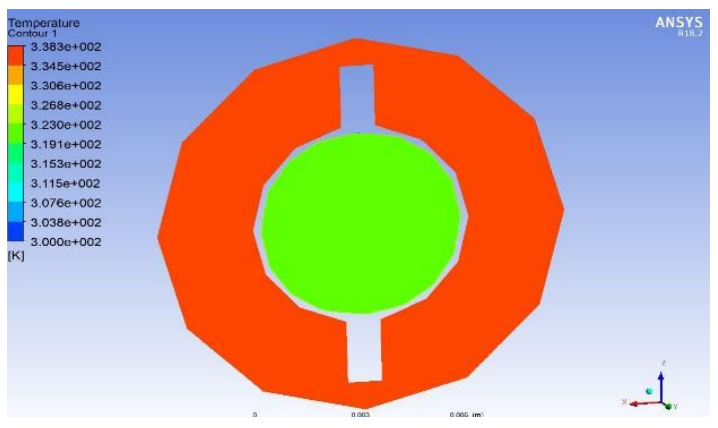

Fig. 21: Temp. Contours for case-2 (0.6 concentration) (cold outlet and hot inlet)

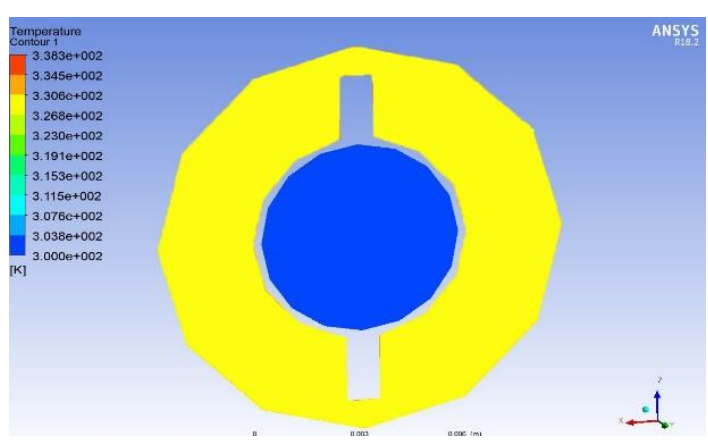

Fig. 22: Temp. Contours for case-2 (0.2 concentration) (cold inlet and hot outlet)

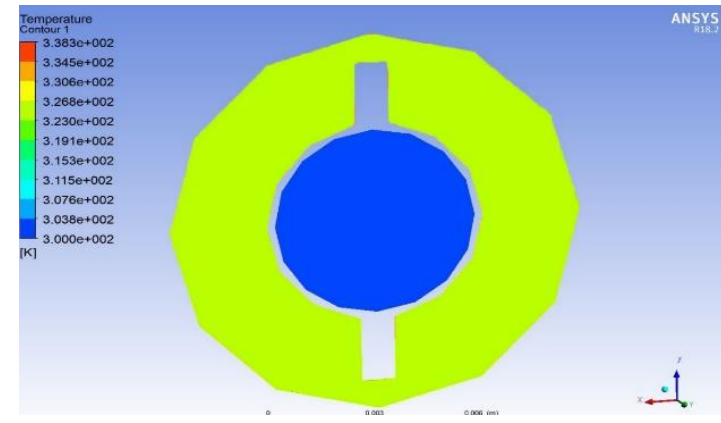

Fig. 23: Temp. Contours for case-2 (0.4 concentration) (cold inlet and hot outlet)

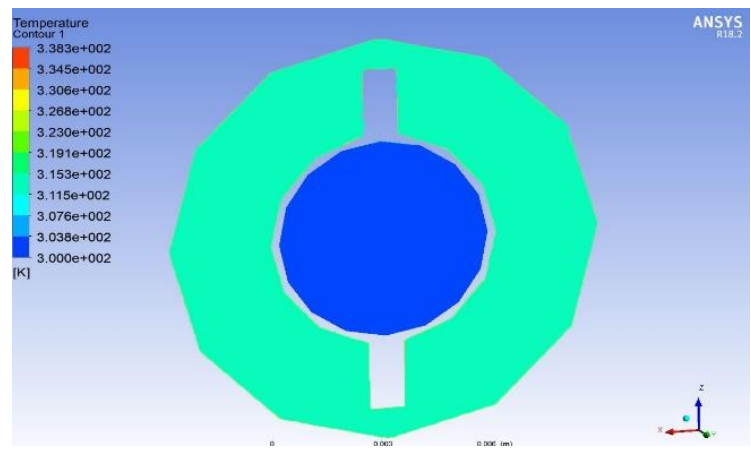

Fig. 24: Temp. Contours for case-2 (0.6 concentration) (cold inlet and hot outlet) 


\section{RESULTS}

Case-1 Results

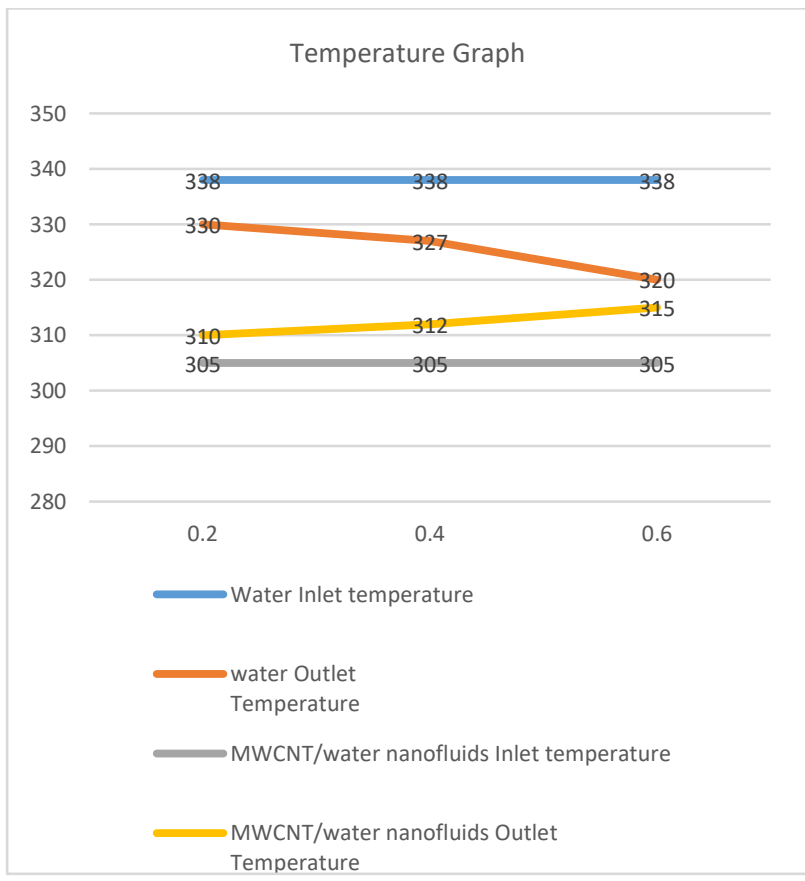

Graph:-1 Temperature Graph for case-1

Case-2 Results

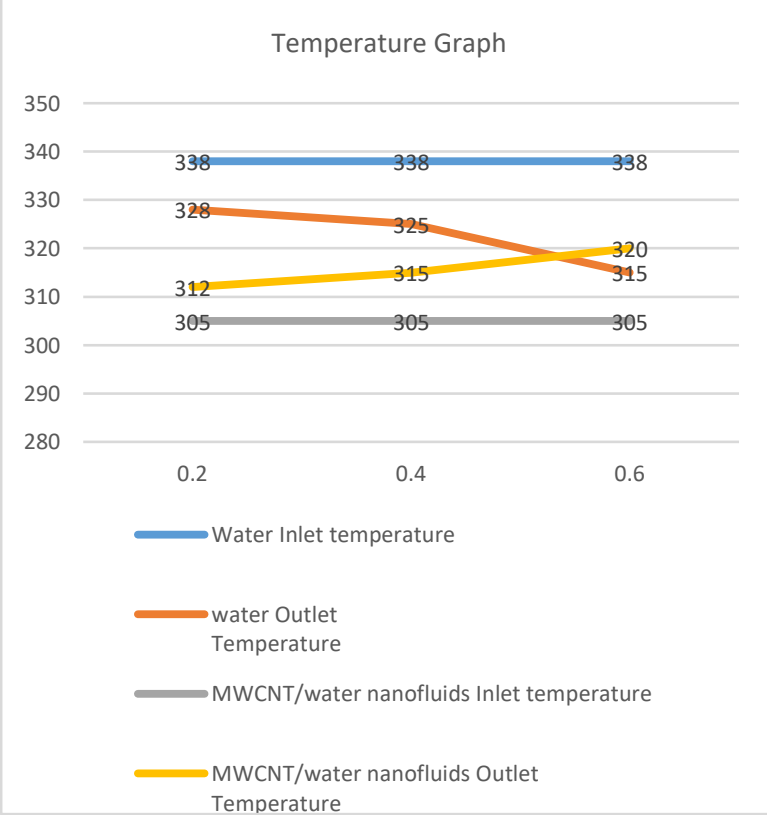

Graph:-2 Temperature Graph for case-2

1) Comparison graph case- 1 and case-2

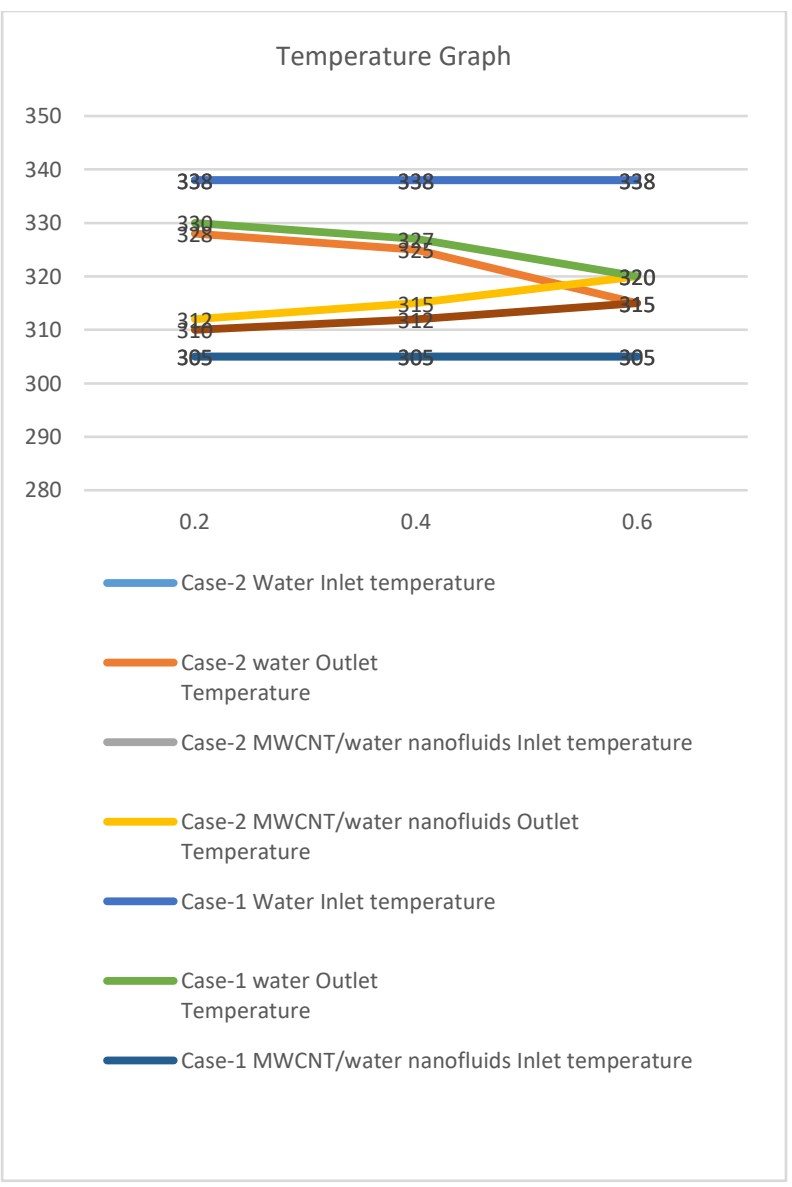

Graph:-3 Comparison graph case-1 and case-2

2) Case-1 Pressure drop (Bar)

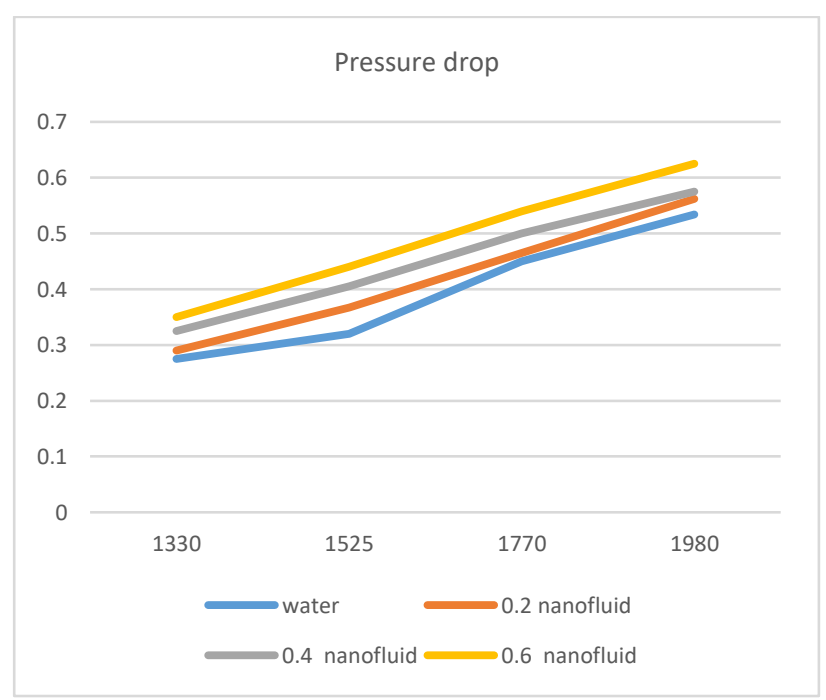

Graph:-4 pressure drop graph

3) Case-2 Pressure drop (Bar) 


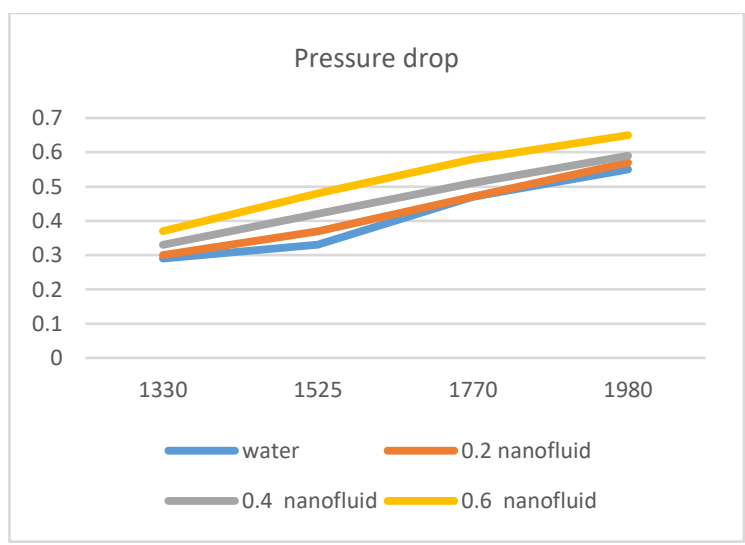

Graph:-5 pressure drop graph

\section{CONCLUSION}

In this analysis, the heat transfer and pressure drop of a double spiral tubular heat exchanger handling MWCNT / water nanofluids were examined using the CFD software package. First, the simulation is verified with hot and cold water and the MWCNT / nanofluid water pressure and temperature are recorded at volume concentrations of $0.2 \%, 0.4 \%$ and $0.6 \%$ with a range of Dean Number of 1300-2000. The final result of the study increases the overall rate of heat transfer in the field. And the pressure drop in the field increases. The leaving water temperature drops to $315 \mathrm{k}$ and the cold leaving temperature rises to $320 \mathrm{k}$. and the total pressure drop increases with increasing temperature. Finally, the CFD data was compared with the previous data. The total pressure drop for case 2 is reduced to 0.65 bar. The overall efficiency of the system can reach from $5 \%$ to $6 \%$.

\section{REFERENCES}

1. Mehdi Bahiraei Reza Rahmani "Recent research contributions concerning use of nanofluids in heat exchangers: Volume 133, 25 March 2018, Pages 137-159

2. Nima Mazaheri, Ali Rizehvandi "Application of a hybrid nanofluid containing graphene nanoplatelet-platinum composite powder in a tripletube heat exchanger equipped with inserted ribs" DOI: 10.1016/j.applthermaleng.2018.12.072 December 2018

3. Reza Rahmani, Ali Yaghoobi "Recent research contributions concerning use of nanofluids in heat exchangers: DOI: 10.1016/j.applthermaleng.2018.01.041 March 2018.

4. Umang K Patel, Prof. Krunal Patel "CFD Analysis Helical Coil Heat Exchanger”, IJARIIE-ISSN(O)-2395-4396, Vol-3 Issue-2 2017.

5. Syed Mohammed Arif, Rashed Ali "CFD Analysis of Heat Transfer in Helical Coil”, International Research Journal of Engineering and Technology (IRJET), Volume: 04 Issue: 03 | Mar -2017.

6. Pramod S. Purandare, Mandar M. Lele, Raj Kumar Gupta "Investigation on thermal analysis of conical coil heat exchanger" Int. J. Heat Mass Transf., 90 (2015), pp. 1188-1196.
7. K. Abdul Hamid, W. H. Azmi, RIzalman Mamat, N. A. Usri and Gohalamhassan Najafi 2015, "Effect of Titanium Oxide Nanofluid Concentration on Pressure drop" ARPN Journal of Engineering and Applied Sciences, Volume 10, Page 7815-7820.

8. Shiva Kumar, K Vasudev Karanth 2013, "Numerical analysis of a Helical Coiled Heat Exchanger using CFD" International Journal of Thermal Technologies, Volume 3, Page 126-130. 